\title{
Teaching Effect and Reform Strategies on Graduation Design for Undergraduates in Information Related Majors in Independent College Based on Psychological Identity
}

\author{
Wei Nai, Lanfei Ma, and Yidan Xing
}

\begin{abstract}
The annual graduation design in universities is the final cultivation process of the comprehensive professional competencies for undergraduates before they end their college career, and is also an important component in the tasks of undergraduate education. Teaching effect of graduation design on one hand depends on the foundation and application ability of professional knowledge of each student, and also depends on the psychological identity on advisor and the topic chosen from the student point of view on the other hand. In this paper, undergraduates who have all finished their graduation design in Department of Electronic and Information Engineering in Independent College $\mathrm{T}$ from the year 2017 to 2019 have been set as study objects, by deeply investigating students' attitudes toward advisors and topics chosen from questionnaire survey, and by analyzing the grade point averages (GPA) of students, the relationship between psychological identity on advisor as well as topic chosen and the teaching effect of graduation design for each student has been found out, and related reform strategies on teaching methods has been discussed.
\end{abstract}

Index Terms-Undergraduates, graduation design, psychological identity, teaching effect analysis, reform strategies.

\section{INTRODUCTION}

It is always the core task for colleges and universities to carry out basic study related to each major and to cultivate the ability in applying professional knowledge as well as the basic ability in scientific research [1]-[7]. And to be specific, the annual graduation design in universities is the final cultivation process of the comprehensive professional competencies for undergraduates before they end their college career, and is also an important component in the tasks of undergraduate education. As far as the graduation design in Electronic and Information Engineering related majors is concerned, the topic of graduation design, which related more closer to the engineering practice and industrial application requirements, would be easier to arouse interests and provoke thoughts from students, and thus would bring better teaching effect; and such better teaching effect is

Manuscript received March 3, 2020; revised October 20, 2020. This work was supported by the 8th Teaching Reform Research Project in Tongji Zhejiang College, and was partly supported by the Zhejiang Soft Science Research Project under Grant No. 2019C35092, Science and Technology Commission of Shanghai Foundation under Grant No. 19DZ1205804, and National Key Research and Development Program of the 13th Five-year Plan in china under Grant No. 2016YFB1200401.

The authors are with the Department of Electronic and Information Engineering, Tongji Zhejiang College, Jiaxing 314051, Zhejiang, China (e-mail: alexni@tongji.edu.cn, 278018176@qq.com strongly related to the psychology identity of the topic of graduation design. Moreover, teaching effect of graduation design depends not only on the topic chosen from the student, but on the professional knowledge, personal charm, and teaching methods of the advisors as well, for those factors related to advisors will also have important impact on students' psychology in their learning process. Therefore, it is of great significance for colleges or universities to take the undergraduates from Electronic and Information Engineering related majors as examples, to study the influence of the students' psychological identity on the advisors and topics of graduation design on the teaching effect, and thus to better organize the process of this certain type of teaching activities.

Till now, researchers have already done many related analysis or research works on the impact of students' psychological identity on teaching effect. Che Wenbo (1988) has explained the concept of "Identity" in his book, and has pointed out that "Identity" is a process in which a person imitates and internalizes the values, norms and features of another person or group, and then forms his or her own behavior pattern [8]. From then on, the concept of "Psychological Identity" has been widely used in the research of higher education teaching. Zhang Qinglin (1995) has pointed out that "Psychological Identity" is a higher form of identity, it has a better effect than the simple identity on rules in education and teaching, the psychological identity on teacher can help students generate better response in emotion, better cooperation in willing, and better action in practice [9]; Li Qinghe (2010) has specifically pointed out the importance of psychological identity in educating university students, and has shown the opinion that psychological identity is the indispensable cornerstone of college and university education [10]. As for the necessity of psychological identity on teaching method and its positive impacts, many related research from different perspectives have already been done. From the macroscopic perspective, He Guoyuan (2016) has studied the psychological identity on the reform of teaching methods, and have underlined the promotion effect on teaching by employing those technical equipments welcomed by students [11]; from the intermediate perspective, Sun Yujiao et al. (2010) have made the analysis of teaching effects based on psychological identity on moral education related courses, and have pointed out that the identity on courses and teachers can develop students' creativity better [12]; Chen Guizhi (2011) has discussed the construction method of students' psychological identity model for the course "Ideological and Moral Cultivation and Legal Basis" [13]; likewise, Chang Sumei et al. (2010) have done a similar 
work on the construction method of psychological identity strategy for the ideological and political theory courses in colleges and universities [14]; while from the microscopic perspective, Zhang Qian (2017) has studied the psychological identity of ethnic minority students on education reform in universities, and have pointed out that psychological identity is of great significance to the formation of self-confidence and internal solid learning driving force for ethnic minority students who do not have quite solid learning foundation during their high-school stage [15]; Cao Hongbo (2014) have carefully studied the singing psychological identity of specific ethnic minority students for specific vocal music courses, and have pointed out that psychological identity can promote cultural understanding and the performance during their vocal music study [16]. Last but not least, there are also a bunch of related research on psychological identity on university teachers. Li Junling et al. (2000) believed an old Chinese Saying "Be close to his teacher and believe in his way", they have founded that university students would like to accept the lectures given by the teacher admired, loved, and respected by them, and the best study effect can thus be achieved, and they have also founded that apart from specialized courses study, students are even likely to internalize their teachers' behavioral advantages into their own behavioral characteristics just because of their psychological identity on their teacher [17]; not come singly but in pairs, Zhang $\mathrm{Na}$ (2012) have also pointed out in her research that $80 \%$ students would like to love a course just because they have psychological identity on the course teacher, and correspondingly, $70 \%$ teachers believe that the positive influence of personal charm on problem students is very significant [18].

From the literature review above, it can be found that the effect of psychological identity on certain type of courses, specific courses, and teaching object have all been reported in some related research, however, graduation design, which plays an important role in undergraduate education and has a special form in its teaching process, has still been seldom discussed focusing on the influence of students' psychological identity on teaching effect. For undergraduates in Electronic and Information Engineering related majors in independent colleges, as the vast majority of them have relatively weaker theoretical study foundation and study initiative compared with the students in ordinary colleges and universities, their study enthusiasm for specified theoretical and practical courses would usually depends on their interest and their love of teachers. In the teaching process of graduation design, if only the way of "From top to bottom" to distribute the topic simply and roughly for those students without considering their psychological identity on the advisors and the topics given, the initiative and creativity of them in completing related study tasks in graduation design will be stifled and limited to a certain extent. Therefore, in this paper, undergraduates who have all finished their graduation design in Department of Electronic and Information Engineering in Independent College $\mathrm{T}$ from the year 2017 to 2019 have been set as study objects, by deeply investigating students' attitudes toward supervisors and topics chosen from questionnaire survey, and by analyzing the grade point averages (GPA) of students, the relationship between psychological identity of supervisor as well as topic chosen and the teaching effect of graduation design for each student has been found out, and related reform strategies on teaching methods has been discussed.

\section{INVESTIGATION AND ANALYSIS ON TEACHING EFFECT OF GRADUATION DESIGN}

\section{A. Investigation Process Design}

As mentioned above, certain undergraduates who have all finished their graduation design in Department of Electronic and Information Engineering in Independent College $\mathrm{T}$ from the year 2017 to 2019 have been set as study objects, those students have been divided into two types according to the characteristics of the graduation thesis defense process of graduation design in this college. One type of students are those ones who have applied and have finally got "Excellent" scores, the other type are those ones who have got other scores. Such division method has mainly taken the way of score evaluation for students into consideration, for a student can only get an "Excellent" score by attending a more strict graduation thesis defense process and performing well. Usually, students who apply for better scores would have more confidence in their graduation design work, the applications for better scores can also reflects their better workloads and more research gains. Moreover, such division can also help to better analyze the effect of students' psychological identity on advisors, topics and the whole guidance processes from advisors in achieving their final scores during the whole graduation design process, especially for the group of students who get "Excellent" scores.

The investigation is carried out in the form of questionnaire. The objects of the questionnaire are just the research objects in this paper, namely the graduate students in the year 2017, 2018 and 2019 who have completed their graduation thesis defense in Electronic and Information Engineering related majors in independent college T. The main content of the questionnaires distributed to those students is quite simple and only have three parts, each part have only 1 question, as shown in Table I. The first part focuses on the psychological identity on the advisors, the question is about whether a student think that his or her advisor can be a model for student and have strong professional knowledge; the second part focuses on the psychological identity on the topics, the question is about whether a student think that the topic of his or her graduation design is properly set by not only taking his or her personal interest in professional techniques, but also taking the workload and difficulty of graduation design into consideration; while the third part focuses on the psychological identity on the whole guidance processes, the question is about whether a student think that his or her advisor can answer questions and give helpful advices timely on key techniques and key problems during the whole graduation design process.

In order to ensure that most of the graduate students can participate in the investigation, questionnaire distribution and collection processes have been done by the form of on-site 
question and answer (Q\&A), and on-site recording at the graduation thesis defense sites of different student groups. That is to say, each student is invited to answer those three questions above after finishing his or her thesis defense and before they left. Considering that students participating in the graduation thesis defense are the their graduation stage, it is urgent for them to deal with various matters related to graduation like thesis modification, the questionnaire has only set up three questions so as not to take up so much time of them.

TABLE I: THREE CORE QUESTIONS DESIGNED ON THE QUESTIONNAIRE AND THE SURVEY DATA COLLECTED

\begin{tabular}{|c|c|}
\hline Question & $\begin{array}{l}\text { Options and survey data } \\
\text { collected }\end{array}$ \\
\hline $\begin{array}{l}\text { 1. Do you think that your advisor can } \\
\text { be a model for student and have strong } \\
\text { professional knowledge? }\end{array}$ & $\begin{array}{l}\text { (1) YES }(634 / 645,98.3 \%) \text {; } \\
\text { (2) NO }(11 / 645,1.7 \%)\end{array}$ \\
\hline $\begin{array}{l}\text { 2. Do you think that the topic of your } \\
\text { graduation design is properly set by } \\
\text { not only taking your personal interest } \\
\text { in professional techniques, but also } \\
\text { taking the workload and difficulty of } \\
\text { graduation design into consideration? }\end{array}$ & $\begin{array}{l}\text { (1) YES }(536 / 645,83.1 \%) \text {; } \\
\text { (2) NO }(109 / 645,16.9 \%)\end{array}$ \\
\hline $\begin{array}{l}\text { 3. Do you think that your advisor can } \\
\text { answer questions and give helpful } \\
\text { advices timely on key techniques and } \\
\text { key problems during the whole } \\
\text { graduation design process? }\end{array}$ & $\begin{array}{l}\text { (1) YES }(645 / 645,100 \%) \text {; } \\
\text { (2) NO }(0 / 645,0 \%)\end{array}$ \\
\hline
\end{tabular}

\section{B. Analysis on the Relationship between Psychological Identity and Final Score of Graduation Design for Individuals}

There are 660 graduate students in total between the year 2017 and 2019 from 6 different Electronic and Information Engineering related majors in independent college $\mathrm{T}$, including communication engineering, electronic information engineering, computer science and technology, electrical engineering and automation, automation, rail transit signal and control. Thus the universality and representativeness of the investigation in major dimension can be ensured. In the investigation, 645 effective questionnaires have been finally collected back. To be specific, questionnaires from 72 students who got "Excellent" scores have all been collected back, and 573 questionnaires from other 588 students have also been collected back.

As already shown in Table I, for the first core question in the investigation "Do you think that your advisor can be a model for student and have strong professional knowledge?" Over $98.3 \%$ students have given their answer "YES", only 11 students have chosen the item "NO". By on-site short interviews with those 11 students, the reason of their choosing "NO" are almost the same as: "I have not been arranged my favorite advisor, and the teacher who finally be my advisor works in a different way I've expected, but I do NOT mean that my advisor is not competence for being a good advisor." And for the third core question in the investigation "Do you think that your advisor can answer questions and give helpful advices timely on key techniques and key problems during the whole graduation design process?" $100 \%$ students have given their answer "YES", and this result gives a positive signal to the teachers' sense of responsibility and professional ability in their process of being a graduation design advisor.

In the questionnaires collected back, the attitudes from individuals are quite different towards the second core question in the investigation "Do you think that the topic of your graduation design is properly set by not only taking your personal interest in professional techniques, but also taking the workload and difficulty of graduation design into consideration?" In order to analyze the differences, opinions from 2 different groups of students have been separated, Fig. 1 shows the opinions on the second core question from the group of student who finally get "Excellent" scores; while Fig. 2 shows the opinions on the same question from the group of other students.

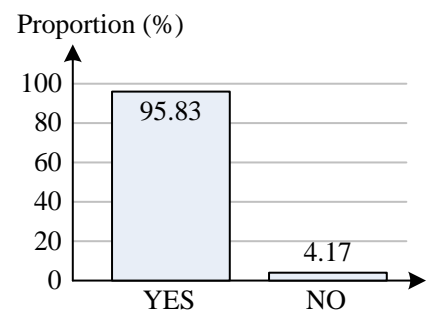

Fig. 1. Distribution of the results on the second core question from the group of students who finally get "Excellent" scores.
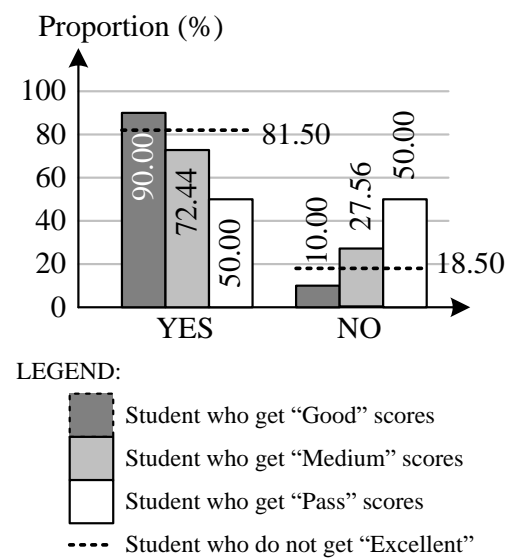

Fig. 2. Distribution of the results on the second core question from the group of other students.

It can be seen from the two figures above that in the group of students who get "Excellent" score, only 3 of them do not feel like their topics of graduation design, they think that the topics chosen are not their favorite research directions. Even though, the proportion of "YES" answer given from the group of students who get "Excellent" score (95.83\%) in Fig. 1 is way much higher than the corresponding proportion of "YES" answer given from the group of other students $(81.50 \%)$ in Fig. 2. If analysis can be done further in the group of other students, it can be seen from Fig. 2 that students get three different final scores "Good" (which is a relatively higher score in this group), "Medium" (which is a score lower than "Good" but higher than "Pass") and "Pass", and it can be found that the proportion of students who hold the positive identity attitudes on their topics is in direct proportion to their final scores. To be specific, $90.00 \%$ of the students who get relatively higher "Good" scores give the answer "YES", while only $72.44 \%$ of the students who get 
"Medium" and $50.00 \%$ of the students who get "Pass" give the same answer.

Combined with the discussion at the beginning of Section 2.2 , it can be analyzed that the vast majority of students have the psychological identity on their advisors, topics, and the whole guidance processes from advisors. The real problem that make students feel confused are in the topic chosen during the whole graduation design process, which also reflects the current situation "From top to bottom" in distributing advisors and topics for students without considering their psychological identity on the advisors and the topics given. Even if some of the students may be "lucky" to choose topics they really like by negotiating with their advisors, it cannot be denied that quite a few students still doing the works they do not really like during their graduation design process, and this situation on some level affect their final scores.

\section{Analysis on the Relationship between Psychological Identity and Score Improvement in Graduation Design for Individuals}

In order to further explore the effect of psychological identity on topic chosen in graduation design, and to analyze the impact of psychological identity on the final teaching effect in a more objective way, apart from simply analyzing the relevant information reflected in the questionnaire and the scores students get in their graduation design, a deeper relationship in score dimension should also be considered. If affected positively by psychological identity on topic chosen, the score of a student may be changed better in his or her graduation design compared with his or her average scores or GPA during the past semesters; similarly, if affected negatively, the score of a student may be get worse in his or her graduation design. Therefore, in this part, GPA of those 645 students participated in the investigation from 6 different Electronic and Information Engineering related majors in independent college $\mathrm{T}$ has been obtained from the educational administration system by mapping their student ID numbers, so as to discuss if there are some relationships between psychological identity on topic chosen and score improvement in graduation design.

The GPA distribution of all 645 students in past semesters have been shown in Fig. 3. There are 97 students have GPAs between 4 and 5 (namely between "Excellent" and "Good"), 305 students have GPAs between 3 and 4 (namely between "Good" and "Medium"), 201 students have GPAs between 2 and 3 (namely between "Pass" and "Medium"), and 42 students have GPAs lower than 2 (which means that they have failed several courses in curriculum).

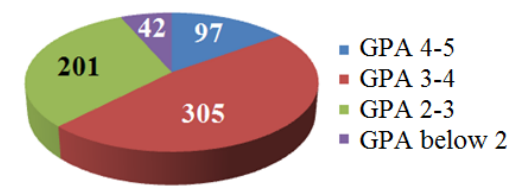

Fig. 2. Distribution of GPAs of all 645 students in their past semesters (with the scores of graduation design excluded).

During the analysis process in this section, the group of students who get "Excellent" in graduation design has been firstly investigated. The distribution of GPAs of those 72 students in their past semesters is shown in Table II. It can be seen that, most students in those 69 students who have the psychological identity on their topic chosen and finally get "Excellent" scores in their graduation design are not just "Top Students", but those students whose GPAs are at 3-4 in their past semesters, and also, there are a bunch of students whose GPAs are only at 2-3 in their past semesters, have shown their abilities in comprehensively applying professional knowledge and skills and get "Excellent" scores finally in their graduation design. Those data above can on some level reflect that, psychological identity, or interest as people usually mentioned, can effectively help students to promote their subjective initiative, maximize their potential in their graduation design study, and make the best of teaching effects from advisors.

TABLE II: DISTRIBUTION OF GPAS IN PAST SEMESTERS OF THE 72 STUDENTS WHO GET “EXCELLENT" SCORES IN GRADUATION DESIGN

69 Students Who Like Their Topic 3 Students Who Do NOT Like Their Chosen in Graduation Design Topic Chosen in Graduation Design

GPA Number of students GPA Number of students

$\begin{array}{llll}4-5 & 28 & 4-5 & 3\end{array}$

$3-4 \quad 31 \quad 3-4 \quad-$

2-3 $\quad 10 \quad 2-3$

Below 2 - Below 2

Similar situation also appears in the 380 students who get "Good" scores in graduation design. The distribution of GPAs of these 380 students in their past semesters is shown in Table III. Even if from the student number point of view, most students in those 342 students, to be specific, 168 students who have the psychological identity on their topic chosen and finally get "Good" scores in their graduation design are those students whose GPAs are on the second level, namely the GPAs at 2-3 in their past semesters, however, the 168 students only take up $44.21 \%$ of those students who get "Good" scores in graduation design; it should be noticed that 133 students with their GPAs lower than 3 finally get "Good" scores in graduation design, and they take up $54.73 \%$ of those students whose GPAs are below 3 in their past semesters. These data has fully shown that, based on the interest of the topic chosen, student whose GPA is not outstanding can still excavate their potential in study, improve the comprehensive application ability of professional knowledge under the guidance of the advisor, and make a breakthrough in their graduation design study process.

TABLE III: DisTRIBUTION OF GPAS IN PAST SEMESTERS OF THE 380 STUDENTS WHO GET “GOOD” SCORES IN GRADUATION DESIGN

\begin{tabular}{|c|c|c|c|}
\hline \multicolumn{2}{|c|}{$\begin{array}{l}342 \text { Students Who Like Their } \\
\text { Topic Chosen in Graduation } \\
\text { Design }\end{array}$} & \multicolumn{2}{|c|}{$\begin{array}{l}38 \text { Students Who Do NOT Like } \\
\text { Their Topic Chosen in Graduation } \\
\text { Design }\end{array}$} \\
\hline GPA & Number of students & GPA & Number of students \\
\hline $4-5$ & 41 & $4-5$ & 25 \\
\hline $3-4$ & 168 & $3-4$ & 13 \\
\hline $2-3$ & 126 & $2-3$ & - \\
\hline Below 2 & 7 & Below 2 & - \\
\hline
\end{tabular}

From another point of view, the 3 students in Table II who do not like their topic chosen in graduation design, are the "Top Students" with GPAs at 4-5. The reason of them to get 
"Excellent" scores in graduation design, is for sure not because of their psychological identity, but their strong study ability and rigorous study attitude towards any study process. Even if they were not assigned the topics they really like, they were still able to complete the graduation design work with high quality in a responsible manner for themselves. On the other hand, "Top Students" with GPAs at 4-5 take up a large proportion in those 38 students in Table III who do not like their topic chosen in graduation design and finally get "Good" scores. Their "decline" in score of graduation design may be affected by many factors, such as busy preparing postgraduate entrance examination or work implementation, etc. But it is undeniable that topic selection is also an important factor in causing the "decline" in score, for they would have lower willing in doing work seriously in research directions which they are not interested in.

\section{REFORM STRATEGIES ANALYSIS ON ENHANCING TEACHING EFFECT IN GRADUATION DESIGN}

From the investigation in Section 2, the relationship between the factors of psychological identity from students and teaching effects in the process of graduation design study can be found. Although at present, personal research preferences in topic choosing process for graduate students in Electronic and Information Engineering related majors in independent college $\mathrm{T}$ has not been considered, only the way of "From top to bottom", namely the way of distributing the topics simply and roughly is adopted, there are still some "lucky" students who can follow the teachers more identified in terms of knowledge and style of teaching, or can be assigned to their more favorite topics. It is of no doubt from the analysis in Section 2, those "lucky" students who have psychological identity on advisors, especially on topics chosen, can generally make outstanding progress and thus get higher scores in their graduation design studies. Therefore, by considering the study ability and study foundation of the students in Electronic and Information Engineering related majors in independent college, and by a more responsible attitude to the study effect, other than the teachers who are supposed to be advisors, both the college and related department (of Electronic and Information Engineering) have the responsibility and obligation to optimize the whole organization process in a better way. By referencing the investigation and analysis in Section 2, and by considering that there are some common problems in the teaching process and teaching effect in the graduation design process in other relevant disciplines, in this section, some teaching reform strategies for graduation design is given as follows based on the psychological identity of students:

\section{A. Attach Importance to the Initiative of Students in Topic Choosing}

For the students who are generally lack of enthusiasm in study in independent colleges, in order to achieve better teach effect in graduation design, the psychological identity must be gained from students, which is also an issue that can be explained by the data in the investigation process. The current "From top to bottom" way of topic distributing for graduate students, might be the most reasonable way in teaching management, and the most convenient way in teaching organization for graduation design, but it does NOT really mean that initiative of students can be ignored, it does NOT really mean that students con not show their opinions in topic choosing. Usually situation in colleges is always like: the number of teachers is limited, and the specialty of each teacher cannot fulfill the requirements from students in organizing topic choosing for graduation design, but still, it would be possible to give full play of students' initiative, to let the students show their preferences in topic choosing, and to find the balance between the professional expertise of teachers and the research direction preference of students. Attach importance to the initiative of students in topic choosing, is for sure the premise of improving teaching effect and achieving better work effect.

\section{B. Further Improving the Charisma and Professional Ability of Teachers}

Even if the investigation in Section 2 shows the psychological identity on advisors is quite good, but as the students are not quite satisfied in their topic chosen, enhancing teaching effect of graduation design depends more on the professional background and the personal charm of teachers. Usually, students would be care about by their advisors not only just on their graduation design, but their everyday life, future career development as well. That is to say, apart from the guidance on the topic of graduation design itself, the psychological identity will be improved and the negative effect on topic chosen may be eliminated if an advisor can give warm, suitable, timely help in case his or her student get confused in other issues apart from study. Moreover, the professional ability of teacher is always the primary factor in generating psychological identity from students. The teachers in independent colleges may have some weak points in certain areas, especially in some interdisciplinary fields, therefore, it is also a necessary way to improve teaching effect that the teachers should always improve and optimize their knowledge system.

\section{CONCLUSIONS}

Aiming at changing the current situation of "From top to bottom" in advisor and topic distribution in organizing graduation design which is the most important content in the curriculum of undergraduate students, and changing the situation of neglecting the consideration of psychological identity from students, in this paper, graduate students from the year 2017 to 2019 are set as the investigation objects, by employing on-site questionnaire and interview, and multi dimension data analysis later on, the psychological identity on advisors, topics and the whole guidance processes from advisors from students, and their impacts on acquiring final scores and professional ability in graduation design have been discussed, and teaching reform strategies corresponds to the investigation results have also been proposed.

Due to the current objective situation of the overall arrangement of teachers and topics for students in organizing graduation design, it would be hard to realize advisor and topic choosing process by completely considering the requirements of students. However, the proposed teaching 
reform strategies can be tried in part of the graduate students in certain majors, and the significant impact of the corresponding strategies on the improvement of teaching effect on graduation design can thus be further discussed in future work.

\section{CONFLICT OF INTEREST}

The authors declare no conflict of interest.

\section{AUTHOR CONTRIBUTIONS}

Wei Nai conducted the research; Lanfei Ma organized the investigation process of questionnaire distribution and collection; Lanfei Ma and Yidan (Yedda) Xing analyzed the data in questionnaire and GPA in educational administration system in independent college T; Wei Nai wrote the paper; all authors had approved the final version.

\section{ACKNOWLEDGMENT}

The authors would like to thank the Mr. Yang Shao, Mr. Lu Liu and Prof. Decun Dong for their helpful advices in the process of writing this paper; and would like to thank all the editors and reviewers for their warm work.

\section{REFERENCES}

[1] D. E. Tanner and D. Andrews, "Technology as a vehicle for education reform," International Journal of Information and Education Technology, vol. 2, no. 4, pp. 415-418, 2012.

[2] D. Cheng, Y. Yin, Z. Zhou, Z. Dong, and X. Guan, "Discussion on engineering education and curriculum reform," International Journal of Information and Education Technology, vol. 3, no. 3, pp. 330-332, 2013.

[3] L. Yuan and C. Wang, "Strengthening scientific research ability of undergraduates, cultivating practical and innovative talents," International Journal of Information and Education Technology, vol. 3 , no. 6, pp. 648-650, 2013.

[4] X. Shi, Z. Xue, and H. Zhang, "A study on the research-oriented teaching courses reform in Chinese colleges and universities," International Journal of Information and Education Technology, vol. 5 no. 4 , pp. 260-264, 2015.

[5] L. Wang, "The information security specialty reform for undergraduate education," International Journal of Information and Education Technology, vol. 7, no. 6, pp. 456-459, 2017.

[6] L. Wang, "The information security specialty education aimed at improving engineering practice ability," International Journal of Information and Education Technology, vol. 7, no. 6, pp. 464-468, 2017.

[7] J. Liu and W. Liu, "Research on talent training model of new applied undergraduate colleges," International Journal of Information and Education Technology, vol. 9, no. 9, pp. 652-660, 2019.

[8] W. Che, Selected Works of Freudism: Volume I, Shenyang, China: Liaoning People's Publishing House, 1988, p. 375.

[9] Q. Zhang, The Application of Contemporary Cognitive Psychology in Teachin, Wiley, Chongqing, China: Southwest Normal University Press, 1995, p. 88.

[10] Q. Li, "The sense of identity in college students: an indispensable cornerstone of college education," University (Academic), no. 3, pp 50-53, 2010.

[11] G. He, "Research on the reform of teaching means based on university students' psychological acceptance," The Science Education Article Cultures, no. 26, pp. 27-28, 2016.

[12] Y. Sun and A. Zhang, "On psychological cognition and the promotion of teaching validity on moral education in universities and colleges," Forum on Contemporary Education, no. 29, pp. 33-34, 2010.

[13] G. Chen, "The strategy of constructing college students' identity psychology in the course of 'Ideological and Moral Cultivation and Legal Basis'," Education and Vocation, no. 12, pp. 74-76, 2011.

[14] S. Chang and X. Zhang, "On the construction of psychological identity mechanism of ideological and political theory course in colleges and universities," Journal of Suihua University, vol. 30, no. 1, pp. 162-164, 2010.

[15] Q. Zhang, "Research on the teaching reform of ethnic minority students based on psychological identity," Popular Science, no. 2, p. 155, 2017.

[16] H. Cao, "Study on the professional vocal music teaching and the minority students' singing psychological identity," Music Space, no. 22, pp. 137-138, 2014

[17] J. Li and G. Liu, "Strive for students' psychological identity and do a good job in teaching," Acta Academiae Medicinae Shandong (Social Science Edition), no. A00, p. 179-181, 2000.

[18] N. Zhang, "Strive for students' psychological identity and do a good job in teaching," Master dissertation, Henan Univ., Kaifeng, Henan, China, 2012.

Copyright (C) 2021 by the authors. This is an open access article distributed under the Creative Commons Attribution License which permits unrestricted use, distribution, and reproduction in any medium, provided the original work is properly cited (CC BY 4.0).

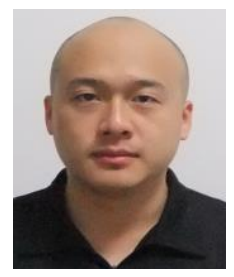

Wei Nai was born in Nanjing, Jiangsu province, China in 1985. He has received B.S. degree in optical information science and technology in Beijing University of Posts and Telecommunications (BUPT), Beijing, China in 2007, the M.S. degree in electromagnetic and microwave technology in BUPT, Beijing, China in 2010, and the Ph.D. degree in transportation information engineering and control in Tongji University, Shanghai, China in 2013. The major field of study is applied broadband communication.

He was a product developing engineer with the China Telecom Shanghai Branch from 2013 to 2014, a postdoctoral researcher with the Postdoctoral Research Station of Control Science and Engineering, Tongji University from 2014 to 2016, a lecturer with the Maglev Transportation Engineering Technology Research and Development Center, Tongji University from 2016 to 2017, and a lecturer with the Department of Electronic and Information Engineering, Tongji Zhejiang College from 2017 to 2019. He is now an associate professor, and the principal of Sino-German exchanges with the Department of Electronic and Information Engineering, Tongji Zhejiang College. The current research interests of him are applied broadband communication, transportation behavior in information environment, and education method for undergraduates and graduates in transportation information related majors, and has published more than 50 papers in international journals and conferences in related area.

Dr. Nai is a member of IEEE, one of the "Outstanding Talents", one of the "Excellent Teachers", and one of the first batch of "Innovation and Entrepreneurship Advisors" in the city of Jiaxing. Dr. Nai is also the Deputy Director of Youth Committee in Xuhui Branch, Shanghai, of China National Democratic Construction Association.

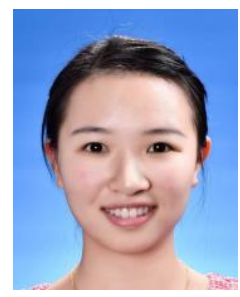

Lanfei Ma was born in Jinhua, Zhejiang province, China in 1998. She is working for B.S. degree in rail transit signal and control, Tongji Zhejiang College, Jiaxing, Zhejiang province, China. The major field of study is transportation information engineering and control related to rail transit.

She has won the third prize of the Mathematical Modeling Competition of American College students. with her major field of study.

The current research interest of her is just the same

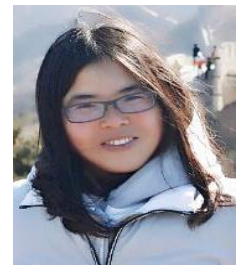

Yidan (Yedda) Xing was born in Weinan, Shaanxi province, China in 1988. She has received the B.S degree in communication engineering in Yan'an University, Yan'an, Shanxi province, China in 2011, the M.S. degree in electronic and communication engineering in Changchun University of Technology, Changchun, Jilin province, China in 2014. The major field of study is broadband wireless communication.

She was an assistant teacher with the Department of Electronic and Information Engineering, Tongji Zhejiang College from 2014 to 2016. She is now a lecturer with the Department of Electronic and Information Engineering, Tongji Zhejiang College. The current research interests of her are broadband wireless communication, and education method for undergraduates and graduates in transportation information related majors. 